\title{
Phase III study of cisplatin with pemtrexed or vinorelbine plus concurrent late course accelerated hyperfractionated radiotherapy in patients with unresectable stage III non-small cell lung cancer
}

\author{
Qian Zhao ${ }^{1,2, *}$, Zhongtang Wang ${ }^{2, *}$, Wei Huang ${ }^{2}$, Qiang Wang ${ }^{3}$, Shuzeng Yu ${ }^{4}$, Tao \\ Zhou $^{2}$, Dan Han ${ }^{2}$, Zhenying Wu ${ }^{5}$, Heyi Gong${ }^{2}$, Hongfu Sun ${ }^{2}$, Jian Zhang ${ }^{2}$, Yumei \\ Wei ${ }^{2}$, Hongsheng $\mathbf{L i}^{2}$, Zicheng Zhang ${ }^{2}$, Haiqun Lin² and Baosheng $\mathbf{L i}^{2}$ \\ ${ }^{1}$ Department of Radiation Oncology, Shandong Cancer Hospital and Institute, Shandong Academy of Medical Sciences, \\ Jinan, Shandong, P.R. China \\ 2 Department of Radiation Oncology, Shandong Cancer Hospital and Institute, Jinan, Shandong, P.R. China \\ 3 Department of Radiation Oncology, People's Hospital of Linzi District, Zibo, Shandong, P.R. China \\ ${ }^{4}$ Department of Radiation Oncology, LiaoCheng People's Hospital, LiaoCheng, Shandong, P.R. China \\ ${ }^{5}$ Department of Radiation Oncology, Second People's Hospital of Dezhou City, Dezhou, Shandong, P.R. China \\ * These authors contributed equally to this manuscript and should be considered co-first authors
}

Correspondence to: BaoSheng Li, email: baoshli1963@163.com

Keywords: chemoradiotherapy, clinical feasibility, vinorelbine, pemetrexed, non-small-cell lung cancer

Received: August 03, 2015

Accepted: January 01, 2016

Published: January 09, 2016

\section{ABSTRACT}

Our aim was to evaluate the efficacy and safety of cisplatin with pemtrexed or vinorelbine and concurrent late course accelerated hyperfractionated radiotherapy (LCAHRT). Patients with unresectable stage III non-small-cell lung cancer (NSCLC) were randomly assigned to two regimens. The experimental (PP) arm included cisplatin, pemtrexed and concurrent LCAHRT based on bilateral lung V20 $=33 \%$. The control (NP) arm used cisplatin, vinorelbine with the same radiotherapy protocol. The primary endpoint was overall survival. Median survival times were $\mathbf{2 6 . 0}$ months (95\% CI 23.2 to 28.7 months) and 28.5 months (95\% CI 17.1 to 39.9 months) for the NP and PP arms, respectively $(P=0.26)$. Median progression-free survival was 12.5 months and 17.5 months in the NP and PP arms $(P=0.07)$. In both arms of the study, there were no differences in overall survival between patients with squamous and nonsquamous NSCLC. The incidences of grade 3 or 4 toxicity were higher in NP than PP arm. With concurrent LCAHRT, pemetrexed/cisplatin was equally as efficacious as vinorelbine/cisplatin, but showed a more favorable toxicity profile.

\section{INTRODUCTION}

Lung cancer is the leading cause of cancer-related deaths worldwide [1]. Only $14 \%$ to $20 \%$ of patients with stage III locally advanced lung cancer are potentially suitable for radical resection because of invasion of adjacent tissues and/or lymph node metastasis $[2,3]$. For patients with unresectable stage III non-small cell lung cancer (NSCLC), the combination of systemic chemotherapy and thoracic radiotherapy (TRT) is now the established standard treatment [4].

It has been proven that concurrent chemoradiotherapy (CCRT) confers a long-term survival benefit at no additional cost over sequential delivery of chemotherapy and TRT to NSCLC patients [5-8]. Further studies to identify the optimal chemotherapy drug combinations concurrent with radiotherapy are in progress. A randomized phase III study by the West Japan Thoracic Oncology Group (WJTOG) [9], which compared third-generation chemoradiotherapy regimens at reduced doses with second-generation regimens at full doses, has suggested that third-generation regimens significantly reduced side effects but failed to prolong patient survival.

Thanks to its favorable toxicity profile, pemetrexed is a promising agent for use in CCRT. Numerous phase I studies have shown that pemetrexed administered at its 
full dose with CCRT is feasible and active [10, 11, 12]. The Cancer and Leukemia Group B (CALGB) conducted a phase II study of carboplatin and pemetrexed with or without cetuximab in patients with NSCLC. They reported that pemetrexed with cetuximab could be recommended as safe for use at its full systemic dose in future trials with concurrent TRT [13]. In addition, the apparent absence of severe toxicity and the high response rates when administering pemetrexed with cisplatin (DDP) and late course accelerated hyperfractionated radiotherapy (LCAHRT) in our earlier phase I study [14] was also encouraging. However, it remains to be determined which has the superior efficacy and toxicity profile for patients with stage III NSCLC: concurrent chemoradiotherapy using pemetrexed or vinorelbine. We therefore designed a multicenter, randomized, controlled, phase III clinical trial to compare the two third-generation regimens.

\section{RESULTS}

\section{Patient characteristics}

Between August 2008 and September 2012, 105 patients were registered in the study. Of those, three patients did not receive the protocol treatment because they were deemed ineligible for the study as a result of being stage IV $(n=1)$, based on a physician's decision ( $n$ $=1)$ or due to performance status $3(n=1)$. Two patients refused to participate in the trial. The trial did not complete accrual and closed in October 2012. One hundred patients were eligible for analysis (48 for the NP arm and 52 for the PP arm). Baseline patient characteristics and demographics are listed in Table 1. There were no statistically significant differences between the two arms with respect to age, performance status, sex, histological subtype and clinical stage.

\section{Treatment administration}

Of the 100 patients, 95 patients completed the CCRT, and 87 patients completed at least two cycles consolidation chemotherapy. The median total radiation dose was $67.5 \pm 6.9 \mathrm{~Gy}$, which equaled a median dose in 2 Gy fractions (EQD2, $T, \alpha / \beta=8.67$ [15]) of $65.9 \pm 6.5$ Gy. In the NP arm, the median delivered dose was 66.9 Gy (range, 51.2 to $79.2 \mathrm{~Gy}$ ), with an average delivered dose of 66.2 Gy. In the PP arm, the median delivered dose was 68.0 Gy (range, 54.0 to $80.6 \mathrm{~Gy}$ ) and the average dose was 67.1 Gy. There was no significant difference between the median radiation dose $(P=0.25)$ in the NP and PP arms.

No patient interrupted radiation because of

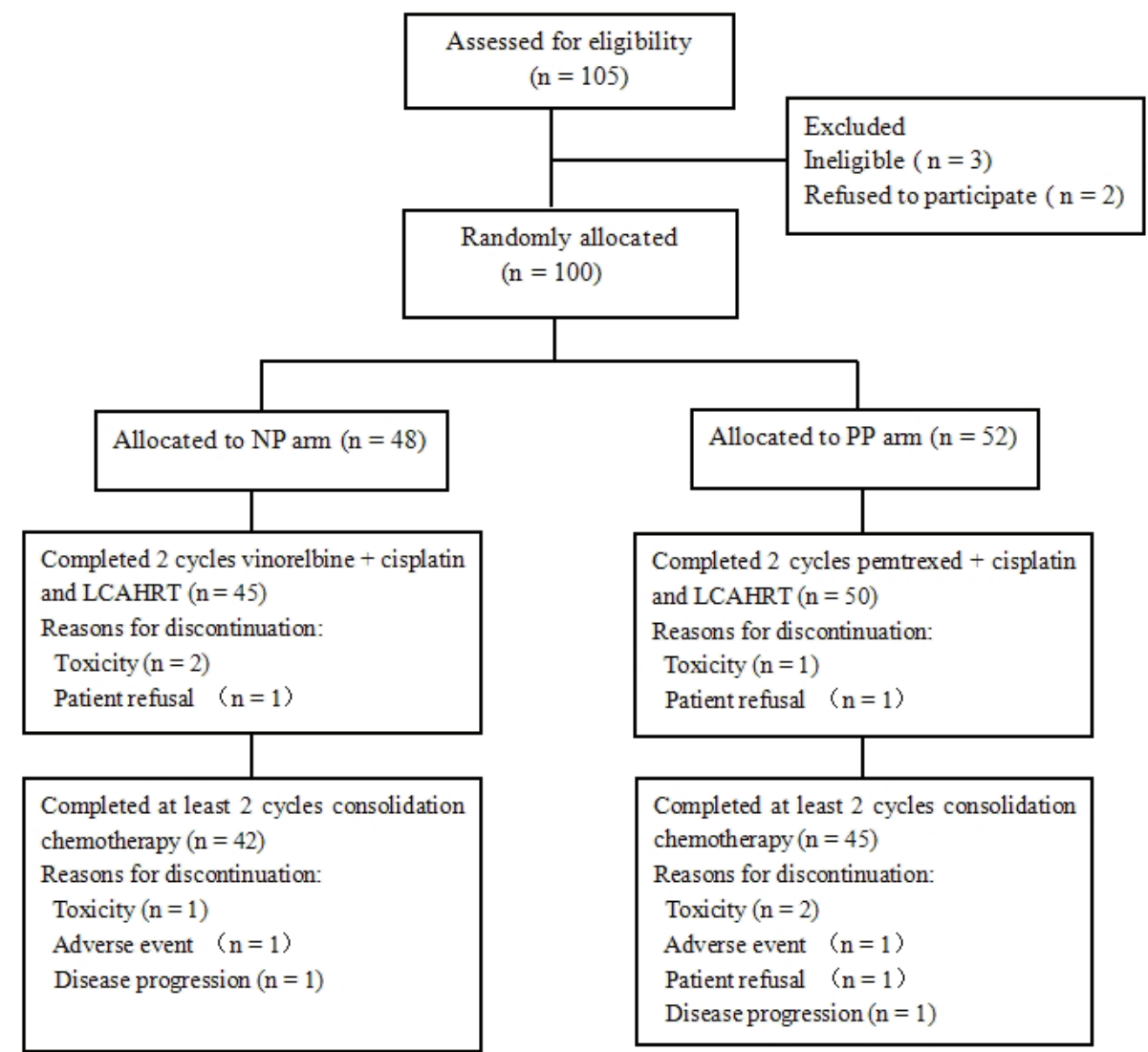

Figure 1: CONSORT diagram. LCAHRT, late course accelerated hyperfractionated radiotherapy. 
Table 1: Patient demographics and clinical characteristics

\begin{tabular}{|c|c|c|c|}
\hline \multirow{2}{*}{ Demographic or Clinical Characteristic } & NP $\operatorname{arm}(n=48)$ & $P P \operatorname{arm}(n=52)$ & \multirow{2}{*}{$P$} \\
\hline & $n(\%)$ & $n(\%)$ & \\
\hline Sex & & & 0.148 \\
\hline Male & $40(83)$ & $37(71)$ & \\
\hline Female & $8(17)$ & $15(29)$ & \\
\hline Age, years & & & 0.099 \\
\hline Median & 57.4 & 60.3 & \\
\hline Range & $34-73$ & $40-75$ & \\
\hline ECOG PS & & & 0.886 \\
\hline 0 & $6(13)$ & $7(13)$ & \\
\hline 1 & $42(87)$ & $45(87)$ & \\
\hline Histology & & & 0.466 \\
\hline Squamous & $32(67)$ & $31(60)$ & \\
\hline Adenocarcinoma & $15(31)$ & $20(38)$ & \\
\hline NSCLC, differentiated & $1(2)$ & $0(0)$ & \\
\hline Large cell & $0(0)$ & $1(2)$ & \\
\hline AJCC, Stage & & & 0.744 \\
\hline IIIA & $20(42)$ & $20(38)$ & \\
\hline IIIB & $28(58)$ & $32(62)$ & \\
\hline Prescribed TTD & & & 0.247 \\
\hline Median (range) in Gy & $66.9(51.2-79.2)$ & $68.0(54.0-80.6)$ & \\
\hline Consolidation & & & 0.312 \\
\hline Chemotherapy & $42(88)$ & $45(87)$ & \\
\hline No & $6(12)$ & $7(13)$ & \\
\hline
\end{tabular}

Abbreviations: $\mathrm{n}$ = number; $\mathrm{ECOG}=$ Eastern Cooperative Oncology Group; PS = Performance status; NSCLC = nonsmall-cell lung cancer; AJCC = American Joint Commission on Cancer staging; TTD = total tumor dose.

\section{Table 2: Objective response}

\begin{tabular}{|l|l|l|l|l|}
\hline \multirow{2}{*}{ Response } & \multicolumn{2}{l|}{ NP $\operatorname{arm}(\boldsymbol{n}=\mathbf{4 8})$} & \multicolumn{2}{l|}{ PP $\operatorname{arm}(\boldsymbol{n}=\mathbf{5 2})$} \\
\cline { 2 - 6 } & $\boldsymbol{n}$ & $\mathbf{\%}$ & $\boldsymbol{n}$ & \% \\
\hline CR & 9 & 18.8 & 17 & 32.7 \\
\hline PR & 35 & 72.9 & 29 & 55.8 \\
\hline SD & 3 & 6.2 & 5 & 9.6 \\
\hline PD & 1 & 2.1 & 1 & 1.9 \\
\hline ORR (CR, PR) & 44 & 91.7 & 46 & 88.5 \\
\hline DCR (CR. PR,SD) & 47 & 97.9 & 51 & 98.1 \\
\hline
\end{tabular}

Abbreviations: $\mathrm{n}=$ number; $\mathrm{CR}=$ complete response; $\mathrm{PR}=$ partial response; $\mathrm{SD}=$ stable disease; $\mathrm{PD}=$ progressive disease; $\mathrm{ORR}=$ objective response rate; $\mathrm{DCR}=$ disease control rate. 
treatment-related toxicity, although two patients declined to continue because the schedule was too exhausting. Three patients were interrupted during chemotherapy. In the NP arm, a dose reduction and a delay of treatment were given to two patients because of grade 4 hematological toxicity. In the PP arm, one patient stopped prematurely because of seriousness eczema on his penis.

\section{Short-term outcome}

The objective response rates were $91.7 \%$ and $88.5 \%$ in the NP and PP arms, respectively (Table 2). Although the response rate in the NP arm was superior to that in the PP arm, this difference was not statistically significant $(P$ $=0.34)$.

\section{Survival outcome}

With median a follow-up time of 29.0 months (range, 3-74 months), the median survival time (MST) was 26.0 months (95\% CI, 23.2 to 28.7 months) in the NP arm and 28.5 months (95\% CI, 17.1 to 39.9 months) in the PP arm $(P=0.26$, Figure 2$)$. Median PFS was 12.5 months ( $95 \%$ CI, 9.48 to 15.5 months) in the NP arm and 17.5 months (95\% CI, 11.6 to 23.4 months) in the PP arm $(P=0.07$, Figure 3$)$. Although there was no clinically significant difference in PFS between the two groups, there was a trend in favor of the PP arm. Overall 2-, 3- and 4-year survival rates were respectively 56.2\% (95\% CI, $49.0 \%-63.4 \%$ ), 30.3\% (95\% CI, 23.3\% - 37.3\%) and 19.0 $(95 \% \mathrm{CI}, 12.2-25.8)$ in the NP arm. The corresponding values were $53.5 \%$ (95\% CI, 46.5\% - 60.5\%), 44.7\% (95\% CI, 37.6\% - 51.8\%) and 28.1\% (95\% CI, 19.4\%-36.8\%) in the PP arm.

The MSTs were 25.0 and 27.0 months for the NP $\operatorname{arm}(P=0.53)$, and 25.5 months and not reached for the $\mathrm{PP}$ arm $(P=0.16)$. There were no significant differences in OS between patients with squamous cell carcinoma (SCC) and non-squamous cell carcinoma (N-SCC) in the two arms. Multivariable analysis using treatment, age, KPS, sex, histology, stage, and the dose of TRT showed that, after controlling for treatment, there were no significant differences associated with survival.

\section{Pattern of relapse}

Relapses were noted in 68 of the 100 patients. Table 3 summarizes the patterns of the sites of first relapse. There was no difference between the two arms $(P=0.84)$.

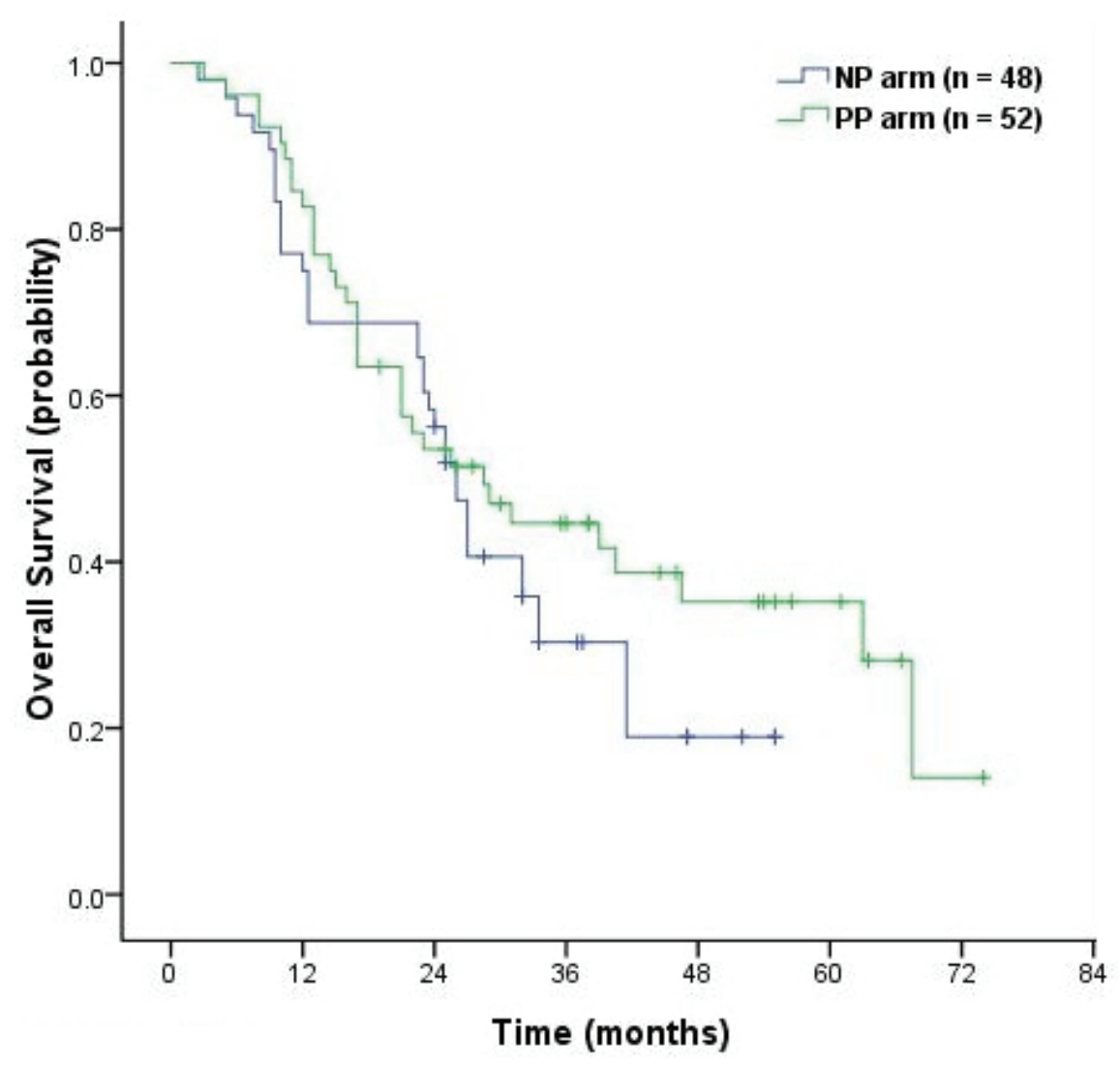

Figure 2: Kaplan-Meier curves of overall survival in the NP and PP arms. 
Table 3: Patterns of failure

\begin{tabular}{|l|l|l|l|l|}
\hline \multirow{2}{*}{ Sites of Failure } & \multicolumn{2}{l|}{ NP $\mathbf{a r m}(\boldsymbol{n}=\mathbf{4 8})$} & \multicolumn{2}{l|}{ PP $\operatorname{arm}(\boldsymbol{n}=\mathbf{5 2})$} \\
\cline { 2 - 5 } & $\boldsymbol{n}$ & $\mathbf{\%}$ & $\boldsymbol{n}$ & \% \\
\hline Locoregional recurrence only & 12 & 25.0 & 11 & 21.1 \\
\hline Distant metastasis only & 16 & 33.3 & 17 & 32.6 \\
\hline Locoregional + distant & 5 & 10.4 & 7 & 13.4 \\
\hline
\end{tabular}

Abbreviations: $\mathrm{n}=$ number.

\section{Safety}

Treatment-related toxicities are summarized in Table 4. The common hematologic side effects in the NP and PP arms were leukopenia and anemia. There were significantly higher rates of leukopenia and anemia in the NP than PP arm. The rates of observed grade 3-4 leukopenia were $20 / 48$ and $11 / 52(P=0.027)$ for the NP and PP arms, respectively, and the rates of grade 3-4 anemia were $8 / 48$ and $5 / 52(P=0.047)$. The incidences of other adverse events, including esophagitis, nausea, vomiting and thrombocytopenia, did not significantly differ.
In the NP arm, grades $1,2,3$ and 4 radiation pneumonitis (RP) were respectively observed in 31 $(64.5 \%), 8(16.6 \%), 1(2 \%)$ and $0(0 \%)$ of the patients, while in the PP arm they were respectively observed in $21(40.4 \%), 10(19.2 \%), 0(0 \%)$ and $0(0 \%)$ of patients $(P$ $=0.021)$. One patient in the NP arm died of pulmonary hemorrhage. The most notable non-hematological adverse event during this phase was esophagitis, which developed to grade 2 or worse in 31 patients: $19(39.6 \%)$ in the NP arm and $12(23.3 \%)$ in the PP arm. No severe late esophageal side effects such as severe stricture or perforation were identified.

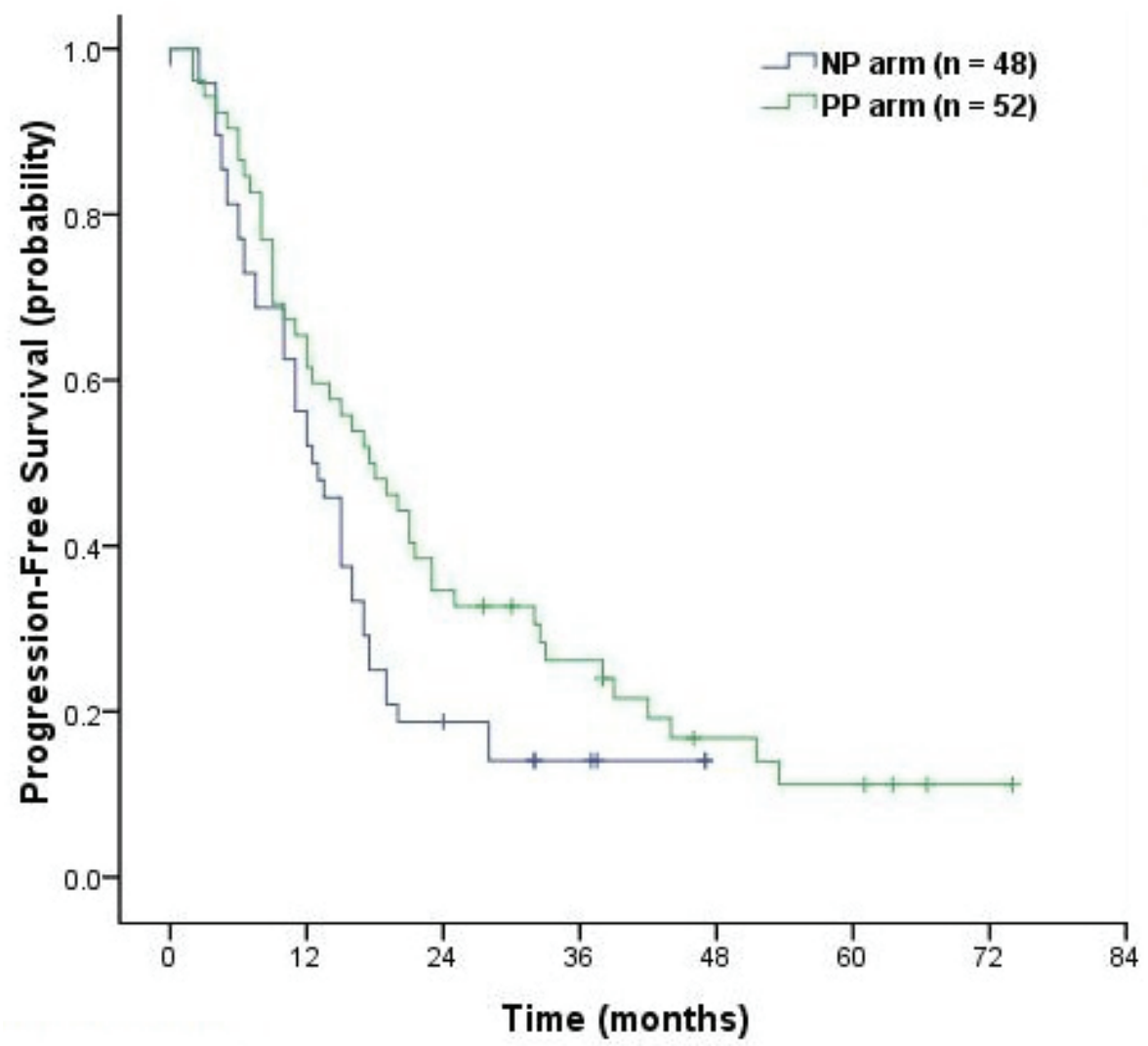

Figure 3: Kaplan-Meier curves of progression-free survival in the NP and PP arms. 
Table 4: Grade $\geq 3$ toxicities observed in the NP and PP arm

\begin{tabular}{|c|c|c|c|c|c|c|c|c|c|}
\hline & \multicolumn{4}{|c|}{ NP $\operatorname{arm}(n=48)$} & \multicolumn{4}{|c|}{$P P$ arm $(n=52)$} & \multirow{3}{*}{$P$} \\
\hline & \multicolumn{2}{|c|}{ Grade } & \multicolumn{2}{|c|}{ Grade $\geq 3$} & \multicolumn{2}{|c|}{ Grade } & \multicolumn{2}{|c|}{ Grade $\geq 3$} & \\
\hline & 3 & 4 & $n$ & $\%$ & 3 & 4 & $n$ & $\%$ & \\
\hline Hematologic toxicity & 23 & 8 & 31 & 64.6 & 13 & 6 & 19 & 36.5 & 0.090 \\
\hline Anemia & 5 & 3 & 8 & 16.7 & 5 & 0 & 5 & 9.6 & 0.047 \\
\hline Leukopenia & 17 & 3 & 20 & 41.7 & 7 & 4 & 11 & 21.2 & 0.027 \\
\hline Thrombocytopenia & 1 & 2 & 3 & 6.3 & 1 & 2 & 3 & 5.8 & 0.103 \\
\hline Non-hematological toxicity & 6 & 0 & 6 & 12.5 & 3 & 0 & 3 & 5.8 & 0.305 \\
\hline Nausea/vomiting & 1 & 0 & 1 & 2.1 & 3 & 0 & 3 & 5.8 & 0.245 \\
\hline Esophagitis & 3 & 0 & 3 & 6.3 & 0 & 0 & 0 & 0 & 0.149 \\
\hline Pulmonary fibrosis & 1 & 0 & 1 & 2.1 & 0 & 0 & 0 & 1.9 & 0.732 \\
\hline Pneumonitis & 1 & 0 & 1 & 2.1 & 0 & 0 & 0 & 0 & 0.032 \\
\hline
\end{tabular}

\section{DISCUSSION}

The results of our phase III trial show no significant difference in OS between the NP and PP arms of the study. This is the first phase III trial designed to compare the PP and NP combinations when administered with concurrent LCAHRT to patients with unresectable stage III NSCLC. From the viewpoint of toxicity, the PP regimen was superior to the NP regimen.

In the context of chemotherapy and concurrent TRT for advanced lung cancer, a number of thirdgeneration regimens have been evaluated to identity the optimal chemotherapy regimen $[16,17]$. Oh et al [18] reported similar outcomes between third-generation regimens entailing paclitaxel, docetaxel or gemcitabine and cisplatin with concurrent TRT. In addition, Wang et al [19] compared weekly paclitaxel/carboplatin and cisplatin/etoposide plus TRT, but detected no significant favorable trend toward survival with either regimen. These two studies did not show third-generation regimens with concurrent TRT to be superior with respect to survival or toxicity in NSCLC patients.

It was noteworthy that, in the present study, toxicity was significantly lower in the PP than NP arm, and there was a trend toward increased PFS in the PP arm. The published outcomes observed the recent phase III studies by Senan et al [20] are consistent with the present study. They investigated PP versus etoposide/cisplatin (EP) plus TRT in patients with advanced nonsquamous NSCLC and observed no significant difference in OS or PFS between the PP and EP arms. However, a significantly lower incidence of grade $3 / 4$ adverse events was observed in the PP arm.

We used LCAHRT on the basis of a prior meta-analysis showing that the use of accelerated or hyperfractionated radiotherapy led to a significant benefit for OS [21]. Repopulation is one of the major factors that hyperfractionated and/or accelerated radiotherapy may better protect against and so improve OS [22, 23]. In the 555-patient trial conducted by Senan et al [20], MSTs were 25.0 and 26.8 months in the EP and PP arms, respectively. The median survival time of 28.5 months in the PP arm in our trial was superior to that in the treatment arm of Senan's study [20]. This survival difference might be due to the use of individualized LCAHRT based on normal tissue constraints. Another trial explored the use of NP with concurrent individualized accelerated radiotherapy based on the normal tissue dose (mean lung dose = $19 \mathrm{~Gy}$ ) [24]. The MST (95\% CI) of 25.0 (19.8-30.3) months was similar to that in the NP arm of our study.

The overall survival of SCC patients in the PP arm in this study was unexpectedly good. Our findings suggest that SCC patients treated with PP and LCAHRT experience an overall survival period similar to N-SCC patients. In the study conducted by Govindan et al [13], patients were randomly assigned to pemetrexed and CCRT with or without cetuximab. Histological analysis revealed no significant difference in OS between the SCC and $\mathrm{N}-\mathrm{SCC}$ patients in the two arms. The study of Gadgeel et al [25] confirmed the same results. Because the number 
of patients is small in the randomized clinical trials, the statistical power for the assessment of survival is low. The use of pemetrexed-based CCRT should be studied further in a large sample of patients with NSCLC classified based on histology types.

The incidence of adverse events noted in the PP arm was significantly better than in the NP arm, particularly with respect to anemia, leukopenia and pneumonitis $(\chi 2$ test $p<0.05)$, though the incidence of grade 3 to 4 esophagitis was not greater than previously reported [2631]. The trial of Jenkins et al [32] confirmed that V20 was a useful factor for predicting the risk of the developing pneumonitis and can aid the selection of optimal treatment plans. The results of our study revealed that based on bilateral lung V20 = 33\%, severe PR using LCAHRT appears to be well tolerated.

The limitations of this study are as follows. The study was terminated short of the planned goal because of slow accrual and a lack of improvement in survival with the pemetrexed/cisplatin treatment. Nonetheless, the incidence of grade 3 or worse toxicity in the PP arm was markedly lower than in the NP arm. Our study enrolled a substantial percentage of patients with SCC. The efficacy of pemetrexed in CCRT is superior in patients with nonsquamous histology was not known when the study was designed. The unplanned subgroup analysis showed no significant difference in survival among patients with squamous and nonsquamous histology in PP regimen. However, due to the small sample number, the study had inadequate power to draw definitive conclusions.

In conclusion, our present findings demonstrate that concurrent pemetrexed with cisplatin and LCAHRT was equally efficacious with a more favorable toxicity profile than NP. However, we will need to wait for the final results of a larger trial to confirm those benefits for the treatment of patients with locally advanced NSCLC.

\section{MATERIALS AND METHODS}

\section{Patient eligibility}

Patients with newly histologically diagnosed, unresectable stage III NSCLC were eligible for this study (Figure 1). Eligible patients were required to have an Eastern Cooperative Oncology Group (ECOG) performance status of $0-1$, to be between 18 and 75 years old, and to have lost no more than $5 \%$ of their weight over the 3 months before enrollment. Laboratory requirements were as follows: a leukocyte count of $\geq 4,000 / \mu \mathrm{L}$, platelets of $\geq 100,000 / \mu \mathrm{L}$, a hemoglobin level $\geq 8 \mathrm{~g} / \mathrm{dL}$, a serum creatinine level $\leq 1.5 \mathrm{mg} / \mathrm{dL}$, a bilirubin $<1 \times$ upper limit of normal (ULN), AST and ALT $<2.5 \times \mathrm{ULN}$, and alkaline phosphatase $<3 \times$ ULN. For staging, all patients underwent $\mathrm{CT}$ of the thorax and abdomen and either a brain CT scan or magnetic resonance imaging. A radio isotopic bone scan was also performed for all patients. Positron emission tomography was strongly recommended for enrollment. All the patients signed an informed consent form that was approved by their institutional review board prior to enrollment. Patients were randomly assigned to the two treatment arms after telephoning the trials center.

\section{Treatment}

The vinorelbine-cisplatin (NP) regimen entailed intravenous (IV) vinorelbine $25 \mathrm{mg} / \mathrm{m}^{2}$ on days 1 and 8 and IV cisplatin $25 \mathrm{mg} / \mathrm{m}^{2}$ on days 1, 2 and 3; cycles were repeated at 21-day intervals. The pemetrexed-cisplatin (PP) regimen entailed IV pemetrexed at $500 \mathrm{mg} / \mathrm{m}^{2}$ on day 1 and cisplatin at $25 \mathrm{mg} / \mathrm{m}^{2}$ on days $1-3$; cycles were repeated at 21-day intervals. In the absence of disease progression or unacceptable toxicity, patients in both arms received at least 2 cycles of consolidation chemotherapy with paclitaxel $45 \mathrm{mg} / \mathrm{m}^{2}$ or vinorelbine $25 \mathrm{mg} / \mathrm{m}^{2}$ on days 1 and 8 and cisplatin $25 \mathrm{mg} / \mathrm{m}^{2}$ on days 1,2 and 3 .

In both arms, chemotherapy dose modifications were based on the leukocyte and platelet counts. If severe hematologic toxicity occurred on a treatment day, chemotherapy was mandatorily held until recovery and then resumed at a $75 \%$ or $50 \%$ dose, as specified. If these toxicities did not abate within 6 weeks from day 1 of the previous chemotherapy cycle, subsequent cycles were stopped.

LCAHRT was administered on the first day of chemotherapy, with the RT given in two phases with no split. Irradiation was administered as conventionally fractionated radiotherapy (CFRT) entailing $5 \times 2$ Gy per week (total dose 40 Gy) in the first phase and LCAHRT in the second phase entailing 1.4 Gy twice a day, with a minimum interval of 6 hours between fractions. An individualized prescribed dose was defined based on bilateral lung V20 = 33\% (the volume of the whole lung receiving $>20 \mathrm{~Gy}$ ). The dose-volume constraints on organs at risk used for plan optimization were as following: bilateral lung, V20 = 35\%; heart, V65 $\leq 33 \%$ (the volume of the whole heart receiving $\geq 65 \mathrm{~Gy}$ ) and $\mathrm{V} 45 \leq 67 \%$ (the volume of the whole heart receiving $\geq$ 45 Gy); liver, V35 $\leq 50 \%$ (the volume of the whole liver receiving $\geq 35$ Gy), spinal cord, $<45$ Gy and esophagus, Dmax $\leq 80$ Gy).

All patients were treated with intensity-modulated radiotherapy (IMRT). The CBCT scans were prospectively acquired weekly in order to register tumor volume changes. Treatment planning was based on CT simulation. The total gross tumor volume (GTV) consisted of the primary tumor and all lymph nodes greater than $1.0 \mathrm{~cm}$ in short axis measurement on CT, or demonstrated positive on a FDG-PET/CT scan. In particular, the target area of the primary lesion was delineated in the routine lung window, and the mediastinal target area was delineated 
in the mediastinal window. In patients with atelectasis, delineation of GTV was based on fused PET-CT images. Regional nodes, including the contralateral hilar, contralateral mediastinal and supraclavicular lymph nodes, were included in the GTV on the condition that imaging manifestations were positive. The clinical tumor volume (CTV) was created by adding a 5-mm margin to the GTV for squamous carcinoma and a 7-mm margin to the GTV for nonsquamous carcinoma. The planning target volume (PTV) was defined as the CTV plus an anisotropic margin of $0.5 \mathrm{~cm}$ for uncertainties of expectation of primary tumor movement, respiratory motion and some setup errors. The goal was to deliver the prescribed dose to at least $95 \%$ of the CTV with $95 \%-105 \%$ dosimetric uniformity and $90 \%$ $110 \%$ coverage of the PTV, while meeting normal tissue constraints according to the respective protocol.

\section{Response evaluation and toxicity}

All eligible patients received a physical examination and blood chemistry studies once a week and CT scan after every two cycles of chemotherapy. The follow-up evaluations consisted of a history, physical examination, and a thoracic CT performed every 3 months during the first 2 years, and every 6 months thereafter. Other imaging examinations were obtained when recurrence was suspected. The Response Evaluation Criteria in Solid Tumors (RECIST) were used to evaluate objective response rate (ORR) as complete response (CR), partial response $(\mathrm{PR})$, stable disease $(\mathrm{SD})$ or progressive disease (PD).

Chemotherapy-related toxicity was judged on the basis of patients' complaints and physical examination, and was graded chiefly at the discretion of the treating physicians, according to the common terminology criteria (CTC) version 3.0.

\section{End-points and statistical analysis}

The primary endpoint of this study was overall survival (OS). Secondary endpoints were progressionfree survival (PFS) and toxic effects. OS was observed from the dates of randomization until death or last followup time. PFS was defined as the time from the dates of randomization to the occurrence of disease progression (whichever occurred first) or death. ORR was defined as the sum of patients with confirmed CR and PR. The Kaplan-Meier method was used to evaluate OS and PFS. The log-rank test was used to compare survival curves for different groups. Toxic effects were examined using the Pearson Chi-Square test. Values of $P<0.05$ were considered significant, and statistical tests were based on a two-sided significance level.

It was projected that the PP regimen would improve the 2-year OS probability of $10 \%$ from the previous NP regimen. Allowing for a $10 \%-15 \%$ ineligibility rate, the plan was to accrue a total of 120 patients in each arm. Statistical analyses were performed using SPSS software version 17.0 (SPSS Inc., Chicago, IL).

\section{ACKNOWLEDGMENTS}

The authors acknowledge the significant contribution of Ying Feng (University of Florida Health Proton Therapy Institute) in the preparation of this manuscript.

\section{FUNDING}

This study was supported by Taishan Scholars Program of Shandong Province, China [ts20120505].

\section{CONFLICTS OF INTEREST}

The authors have declared no conflicts of interest.

\section{REFERENCES}

1. Jemal A, Siegel R, Ward E, Murray T, Xu J, Thun MJ. Cancer statistics, 2007. CA Cancer J Clin. 2007; 57: 43-66.

2. Yang P, Allen MS, Aubry MC, Wampfler JA, Marks RS, Edell ES, Thibodeau S, Adjei AA, Jett J, Deschamps C. Clinical features of 5,628 primary lung cancer patients: experience at Mayo Clinic from 1997 to 2003. Chest. 2005; 128: 452-462.

3. Goya T, Asamura H, Yoshimura H, Kato H, Shimokata K, Tsuchiya R, Sohara Y, Miya T, Miyaoka E. Prognosis of 6644 resected non-small cell lung cancers in Japan: a Japanese lung cancer registry study. Lung Cancer. 2005; 50: 227-234.

4. O’Rourke N, Roqué I Figuls M, Farré Bernadó N, Macbeth F. Concurrent chemoradiotherapy in non-small cell lung cancer. Cochrane Database Syst Rev 2010:CD002140

5. Vergnenegre A, Combescure C, Fournel P, Bayle S, Gimenez C, Souquet PJ, Lena H, Perol M, Delhoume JY; GFPC (Groupe Français de Pneumo-Cancérologie). Cost-minimization analysis of a phase III trial comparing concurrent versus sequential radiochemotherapy for locally advanced non-small-cell lung cancer (GFPC-GLOT 95-01). Ann Oncol. 2006; 17: 1269-1274.

6. Aupérin A, Le PC, Rolland E, Curran WJ, Furuse K, Fournel P, Belderbos J, Clamon G, Ulutin HC, Paulus R, Yamanaka T, Bozonnat MC, Uitterhoeve A, et al. Meta-analysis of concomitant versus sequential radiochemotherapy in locally advanced non-small-cell lung cancer. J Clin Oncol. 2010; 28: 2181-2190.

7. Fournel P, Robinet G, Thomas P, Souquet PJ, Léna H, Vergnenégre A, Delhoume JY, Le TJ, Silvani JA, Dansin E, Bozonnat MC, Daurés JP, Mornex F, et al. Randomized 
phase III trial of sequential chemoradiotherapy compared with concurrent chemoradiotherapy in locally advanced non-small-cell lung cancer: Groupe Lyon-Saint-Etienne d'Oncologie Thoracique-Groupe Francais de PneumoCancerologie NPC 95-01 Study. J Clin Oncol. 2005; 23: 5910-5917.

8. Curran WJ Jr, Paulus R, Langer CJ, Komaki R, Lee JS, Hauser S, Movsas B, Wasserman T, Rosenthal SA, Gore E, Machtay M, Sause W, Cox JD. Sequential vs. concurrent chemoradiation for stage III non-small cell lung cancer: randomized phase III trial RTOG 9410. J Natl Cancer Inst. 2011; 103: 1452-1460.

9. Yamamoto N, Nakagawa K, Nishimura Y, Tsujino K, Satouchi M, Kudo S, Hida T, Kawahara M, Takeda K, Katakami N, Sawa T, Yokota S, Seto T, et al. Phase III study comparing second- and third-generation regimens with concurrent thoracic radiotherapy in patients with unresectable stage III non-small-cell lung cancer: West Japan Thoracic Oncology Group WJTOG0105. J Clin Oncol. 2010; 28: 3739-3745.

10. Niho S, Kubota K, Nihei K, Sekine I, Sumi M, Sekiguchi R, Funai J, Enatsu S, Ohe Y, Tamura T. Dose-escalation study of thoracic radiotherapy in combination with pemetrexed plus Cisplatin followed by pemetrexed consolidation therapy in Japanese patients with locally advanced nonsquamous non-small-cell lung cancer. Clin Lung Cancer. 2013; 14: 62-69.

11. Cardenal F, Arnaiz MD, Moran T, Jové J, Nadal E, Porta R, Solé JM, Brao I, Palmero R, Fuentes R, Núñez I, Caveda E, Cassinello A. Phase I study of concurrent chemoradiation with pemetrexed and cisplatin followed by consolidation pemetrexed for patients with unresectable stage III nonsmall cell lung cancer. Lung Cancer. 2011; 74: 69-74.

12. Mornex F, Peignaux K, Germain T, Wautot V, Chouaki N, Bourayou N, Tourani JM. Phase I study of pemetrexed and cisplatin with concurrent high-dose thoracic radiation after induction chemotherapy in patients with unresectable locally advanced non-small cell lung cancer. Lung Cancer. 2013; 80: 68-74.

13. Govindan R, Bogart J, Stinchcombe T, Wang X, Hodgson L, Kratzke R, Garst J, Brotherton T, Vokes EE. Randomized phase II study of pemetrexed, carboplatin, and thoracic radiation with or without cetuximab in patients with locally advanced unresectable non-small-cell lung cancer: Cancer and Leukemia Group B trial 30407. J Clin Oncol. 2011; 29: 3120-3125.

14. Li BS, Gong HY, Huang W, Yi Y, Yu JM, Wang ZT, Zhang ZC, Sun HF, Li HS, Wang LY. Phase I study of pemetrexed, cisplatin, and concurrent radiotherapy in patients with locally advanced non-small cell lung cancer. Am J Clin Oncol. 2012; 35: 115-119.

15. Van Baardwijk A, Bosmans G, Bentzen SM, Boersma L, Dekker A, Wanders R, Wouters BG, Lambin P, De Ruysscher D. Radiation dose prescription for non-small-cell lung cancer according to normal,tissue dose constraints: an in silico clinical trial. Int J Radiat Oncol Biol Phys. 2008; 71: $1103-1110$.

16. Sugawara $\mathrm{S}$, Maemondo $\mathrm{M}$, Tachihara $\mathrm{M}$, Inoue $\mathrm{A}$, Ishimoto O, Sakakibara T, Usui K, Watanabe H, Matsubara N, Watanabe K, Kanazawa K, Ishida T, Saijo Y, Nukiwa $\mathrm{T}$. Randomized phase II trial of uracil/tegafur and cisplatin versus vinorelbine and cisplatin with concurrent thoracic radiotherapy for locally advanced unresectable stage III non-small-cell lung cancer: NJLCG 0601. Lung Cancer. 2013; 81:91-96.

17. Liew MS, Sia J, Starmans MH, Tafreshi A, Harris S, Feigen M, White S, Zimet A, Lambin P, Boutros PC, Mitchell P, John T. Comparison of toxicity and outcomes of concurrent radiotherapy with carboplatin/paclitaxel or cisplatin/ etoposide in stage III non-small cell lung cancer. Cancer Med. 2013; 2:916-924.

18. Oh IJ, Kim KS, Kim YC, Ban HJ, Kwon YS, Kim YI, Lim SC, Chung WK, Nam TK, Song JY, Yoon MS, Ahn SJ. A phase III concurrent chemoradiotherapy trial with cisplatin and paclitaxel or docetaxel or gemcitabine in unresectable non-small cell lung cancer: KASLC 0401. Cancer Chemother Pharmacol. 2013; 72: 1247-1254.

19. Wang L, Wu S, Ou G, Bi N, Li W, Ren H, Cao J, Liang J, Li J, Zhou Z, Lv J, Zhang X. Randomized phase II study of concurrent cisplatin/etoposide or paclitaxel/carboplatin and thoracic radiotherapy in patients with stage III non-small cell lung cancer. Lung Cancer. 2012; 77: 89-96.

20. Senan S, Brade AM, Wang LH, Vansteenkiste JF, Dakhil SR, Biesma B, Aguillo MM, Aerts J, Govindan R, Belén RV, Lewanski CR, Gandara DR, Choy H. Final overall survival (OS) results of the phase III PROCLAIM trial: Pemetrexed (Pem), cisplatin (Cis) or etoposide (Eto), Cis plus thoracic radiation therapy (TRT) followed by consolidation cytotoxic chemotherapy (CTX) in locally advanced nonsquamous non-small cell lung cancer (nsNSCLC). J Clin Oncol. 33, 2015 (suppl; abstr 7506).

21. Mauguen A, Le PC, Saunders MI, Schild SE, Turrisi AT, Baumann M, Sause WT, Ball D, Belani CP, Bonner JA, Zajusz A, Dahlberg SE, Nankivell M, et al. Hyperfractionated or accelerated radiotherapy in lung cancer: an individual patient data meta-analysis. J Clin Oncol. 2012; 30:2788-2797

22. Mehta M, Scrimger R, Mackie R, Paliwal B, Chappell R, Fowler J. A new approach to dose escalation in non-smallcell lung cancer. Int J Radiat Oncol Biol Phys. 2001; 49:2333.

23. Saunders M, Dische S, Barrett A, Harvey A, Gibson D, Parmar M. Continuous hyperfractionated accelerated radiotherapy (CHART) versus conventional radiotherapy in non-small-cell lung cancer: a randomised multicentre trial. CHART Steering Committee. Lancet. 1997; 350:161165.

24. Van Baardwijk A, Reymen B, Wanders S, Borger J, Ollers M, Dingemans AM, Bootsma G, Geraedts W, Pitz C, Lunde R, Peters F, Lambin P, De Ruysscher D. Mature results of 
a phase II trial on individualised accelerated radiotherapy based on normal tissue constraints in concurrent chemoradiation for stage III non-small cell lung cancer. Eur J Cancer. 2012; 48: 2339-2346.

25. Gadgeel SM, Ruckdeschel JC, Patel BB, Wozniak A, Konski A, Valdivieso M, Hackstock D, Chen W, Belzer K, Burger AM, Marquette L, Turrisi A. Phase II study of pemetrexed and cisplatin, with chest radiotherapy followed by docetaxel in patients with stage III non-small cell lung cancer. J Thorac Oncol. 2011; 6: 927-933.

26. Segawa Y, Kiura K, Takigawa N, Kamei H, Harita S, Hiraki S, Watanabe Y, Sugimoto K, Shibayama T, Yonei T, Ueoka H, Takemoto M, Kanazawa S, et al. Phase III trial comparing docetaxel and cisplatin combination chemotherapy with mitomycin, vindesine, and cisplatin combination chemotherapy with concurrent thoracic radiotherapy in locally advanced non-small-cell lung cancer: OLCSG 0007. J Clin Oncol. 2010; 28: 3299-3306.

27. Kawaguchi T, Takada M, Ando M, Okishio K, Atagi S, Fujita Y, Tomizawa Y, Hayashihara K, Okano Y, Takahashi F, Saito R, Matsumura A, Tamura A. A multi-institutional phase II trial of consolidation S-1 after concurrent chemoradiotherapy with cisplatin and vinorelbine for locally advanced non-small cell lung cancer. Eur J Cancer. 2012; 48:672-677.

28. Naito Y, Kubota K, Nihei K, Fujii T, Yoh K, Niho S, Goto K, Ohmatsu H, Saijo N, Nishiwaki Y. Concurrent chemoradiotherapy with cisplatin and vinorelbine for stage III non-small cell lung cancer. J Thorac Oncol. 2008; 3:617622 .

29. Gadgeel SM, Ruckdeschel JC, Patel BB, Wozniak A, Konski A, Valdivieso M, Hackstock D, Chen W, Belzer K, Burger AM, Marquette L, Turrisi A. Phase II study of pemetrexed and cisplatin, with chest radiotherapy followed by docetaxel in patients with stage III non-small cell lung cancer. J Thorac Oncol. 2011; 6:927-933.

30. Choy H, Schwartzberg LS, Dakhil SR, Garon EB, Gerber DE, Choksi JK, Govindan R, Peng G, Koustenis A, Treat J, Obasaju C. Phase 2 study of pemetrexed plus carboplatin, or pemetrexed plus cisplatin with concurrent radiation therapy followed by pemetrexed consolidation in patients with favorable-prognosis inoperable stage IIIA/B non-small-cell lung cancer. J Thorac Oncol. 2013; 8:1308-1316.

31. Horinouchi H, Sekine I, Sumi M, Noda K, Goto K, Mori K, Tamura T. Long-term results of concurrent chemoradiotherapy using cisplatin and vinorelbine for stage III non-small-cell lung cancer. Cancer Sci. 2013; 4:93-97.

32. Jenkins P, D'Amico K, Benstead K, Elyan S. Radiation pneumonitis following treatment of non-small cell lung cancer with continuous hyperfractionated accelerated radiotherapy (CHART). Int J Radiat Oncol Biol Phys. 2003; 56: 360-366. 